\title{
La amistad en el cine bélico: estratificación, desdoblamiento del yo y empatía.
}

Friendship in war cinema: stratification, splitting of self and empathy.

DOI: 10.32870/sincronia.axxv.n79.2a21

\author{
María Pilar Panero García \\ Universidad de Valladolid. (ESPAÑA) \\ CE: mariapilar.panero@uva.es / ID ORCID: 0000-0001-7346-0778
}

Esta obra está bajo una Licencia Creative Commons Atribución-NoComercial 4.0 Internacional

Recibido: $26 / 06 / 2020$

Revisado: $18 / 10 / 2020$

Aprobado: $17 / 11 / 2020$

\section{RESUMEN}

Este trabajo tiene como finalidad abordar el tema de la amistad el cine bélico, entendida ésta como la que comprende todas las variantes de la palabra amor, o lo que es lo mismo, entendida como la philía de los antiguos. Estas narraciones tienen la ventaja de que plantean la existencia de conflictos sociales, el más violento es la guerra, que a su vez actúan como generadores de sentimientos y pasiones de toda índole. Lo que se pretende, entonces, es hacer un análisis de las diferentes filias en situaciones límite para el hombre moderno.

Palabras clave: Cine y literatura. Filia-fobia. Jerarquía. Viaje moral. Otredad.

\section{ABSTRACT}

This work aims to address the theme of friendship war cinema, understood as one that includes all the variants of the word love, or what is the same, understood as the philía of the ancients. These narratives have the advantage that they raise the existence of social conflicts, the most violent is war, which in turn acts as generators of feelings and passions of all kinds. What is intended, then, is to make an analysis of the different philias in borderline situations for modern man.

Keywords: Cinema and Literature. Philia-phobia. Hierarchy. Moral travel. Otherness. 


\section{Introducción}

Tanto el cine como la literatura son un medio para el conocimiento del hombre; y ambos, además de compartir la palabra como medio de expresión para contar historias, comparten estructuras y temas, por lo que son constantes las influencias entre un arte y otro. De los dos surge un afán por ahondar en las dos caras de la naturaleza humana, en sus dos principios esenciales, el de cohesión o amor, y el de dispersión u odio. Nos centraremos en cuatro películas inolvidables - La gran ilusión (Renoir, 1937), Apocaliypse Now (Coppola, 1979), La cruz de hierro (Peckinpah, 1976) y La delgada línea roja (Malick, 2000)-, pero tendremos en consideración otras en las que el fantasma de la guerra está presente, aunque sea de forma indirecta. En Casablanca (Curtiz, 1943), Gilda (Vidor, 1946), Encrucijada de odios (Dmytryk, 1947), El tercer hombre (Reed, 1949), etc., debido al conflicto militar lo que se expone es el conflicto humano relacionado con la guerra. A partir de ellas reflexionaremos sobre el tema de la amistad en sentido amplio ${ }^{1}$, que ya trataron los pensadores más influyentes del helenismo -Sócrates, Platón y Aristóteles-, del cristianismo medieval como Tomás de Aquino y el mundo moderno, es decir, secularizado, burgués y plural de pensadores como Kant (Laín, 1986, p. 155).

\section{Las barreras de clase y la amistad: La gran ilusión}

En la película de Jean Renoir el estado de la naturaleza ha desaparecido por completo y solo tenemos muestras de diversas clases sociales obligadas a convivir, o a soportarse, en un campo de concentración. En esta obra, cuyo carácter es marcadamente pacifista, las barreras de clase se imponen sobre las barreras nacionales, y, siendo esto así, no es de extrañar que las grandes amistades surjan de dicha conciencia. La amistad surge al margen de las condiciones socio-

\footnotetext{
1 P. Macherey toma de E. Dugas esta división de los griegos: "Los antiguos dan a la palabra philía la extensión que nosotros damos a la palabra amor. Nosotros decimos: el amor paterno, el amor filial, etc.; ellos dices: la amistad paterna, la amistad filial. La philía comprende todos los afectos: el amor propiamente dicho, entre dos personas del mismo sexo o de diferentes sexos (philía erōtiké), al amor del género humano o philantrōpía, y la amistad en sentido estricto (philia hetairiké). La afinidad de los elementos que recuerda la simpatía entre las personas se llama propiamente philotēs" (2000, p. 61).
} 
económicas, porque surge de la distinción de diversas ideologías, en resumidas cuentas, es un posicionamiento del yo frente a los otros, una forma de entender y de estar en el mundo. Renoir aborda la crítica contra la propaganda ideológica de los estados, que intentaban hacer ver la fraternidad entre individuos en combate por el solo hecho de luchar en el mismo bando. En definitiva, se trata de una crítica humanista de la ilusión de la guerra.

Para José María Caparrós Lera (1998, pp. 39-40) es una película de reconstitución histórica (no confundir con reconstrucción histórica) lo que la hace un medio de investigación histórica y un recurso didáctico. Al margen del subjetivismo del director, nos sirve para saber cómo piensa una generación concreta de un hecho histórico del pasado evocándolo en un ejercicio de historiografía moderna.

El filme comienza cuando el capitán Boëldieu (Pierre Fresnay) y el teniente Maréchal (Jean Gabin) son derribados por unos alemanes y capturados por su capitán von Rauffestein (von Stroheim) que los invita cortésmente a cenar. Los dos oficiales franceses son trasladados al campo de Hallsbach, donde compartirán celda con otros prisioneros que planean una fuga, pero cuando están a punto de finalizar el túnel secreto son trasladados de campo de concentración. En Wintersborn se reencuentran con el capitán von Rauffestein, y entre éste y Boëldieu surge una fuerte amistad fundada en vínculos de clase. Boëldieu planifica una fuga en la que Maréchal y el comerciante burgués y judío Rosenthal (Marcel Dalio) escapan. Mientras que Boëldieu es abatido por su amigo alemán, Maréchal y Rosenthal se esconden en la granja de Elsa (Dita Pardo), una viuda alemana que vive con su hija, y con la que Maréchal tendrá relaciones amorosas. Cuando los dos franceses consiguen llegar a Suiza y la fuga, tan anhelada en otros momentos, se hace forzosa, y es en ese momento cuando Rosenthal enuncia la tesis de la película: "No puedes ver una frontera. Son una invención de los hombres. A la naturaleza le importa un bledo".

La gran ilusión evita mostrar directamente los horrores de la guerra, pero nos sugiere sus consecuencias en la conducta de unos personajes cargados de ternura. El campo de concentración se muestra como un espacio de juego en un intento de evadirse, más que del campo, de la realidad cotidiana; la opresión es más psíquica que física. La paradoja es que los prisioneros ven a través de 
los barrotes a niños que juegan a soldados en el exterior, mientras que ellos dentro juegan como niños. La aparente frivolidad - hacen teatro, se travisten, cantan "La Marsellesa" para celebrar la toma de la fortaleza de Douamond, llevan de un campo a otro sus raquetas de tenis, etc. - es la válvula de escape de unos seres humanos encerrados en un medio hostil en el que solo poseen sus rasgos diferenciadores, el respeto mutuo, el compañerismo y la amistad. Tanto los prisioneros como los carceleros son miembros de una comunidad artificial en la que la nostalgia de un tiempo en paz no es capaz de anular su esencia humanizada, sus sentimientos.

Según la propaganda patriótica el soldado es símbolo de todas las virtudes nacionales, y el heroísmo y la camaradería son algo espontáneo y natural entre aquellos que visten el mismo uniforme, pertenecen a la misma raza o, incluso, están dentro del mismo grupo de naciones aliadas. Pero en la película de Renoir la amistad como afinidad política no funciona: los alemanes son condescendientes con sus cautivos; el campo de prisioneros es una torre de Babel en la que los mismos aliados no consiguen entenderse, los franceses dicen a los ingleses que tienen casi a punto un túnel para la fuga, pero la diferencia de idioma impide que el gesto generoso tenga validez; y los mismos franceses pasan por alto el sentimiento nacional.

Boëldieu es un aristócrata al que le gusta la ópera y se sorprende porque su compañero Maréchal prefiera el ciclismo. Ambos comparten habitación a su llegada a Hallsbach con el hijo de unos ricos banqueros judíos Rosenthal, con un obrero, dos profesores y un actor. Boëldieu no se implica en las actividades de los otros, en la obra de teatro, por ejemplo, mantiene la distancia con unos compatriotas a los que considera plebeyos, aunque los respeta y será capaz del mayor de los sacrificios, morir para facilitarle la fuga a dos compañeros demostrando así su sentido del honor y del deber. Sin embargo, sí comparte el orgullo de casta y el sentido del honor con von Rauffesntein con el que, a pesar del idioma y de encontrarse en bandos ideológicos y políticos enfrentados, le resulta muy fácil el diálogo y el entendimiento. Rauffenstein se verá obligado a disparar contra su amigo, su compañero de clase, contemplará impotente su agonía y tomará conciencia de que el seguir aferrado a su viejo código del honor no lo librará del sufrimiento tras haber matado a su amigo. Tanto Boëldieu como Rauffenstein comprenden que en el mundo en el que viven la 
excelencia del ser aristocrático, areté, ya no funciona, por lo que sostienen su "estar en el mundo" del que Aristóteles habla en un sentimiento de carácter íntimo, una amistad basada en la igualdad. La flor del geranio, lo único bello y natural en medio de la crueldad, que el alemán corta para su amigo muerto es un símbolo de todo lo que la guerra arrebata a los hombres.

El cautiverio de los personajes tiene tintes de ser más psíquico que físico. El mejor ejemplo es Elsa, que siendo libre es la más oprimida. Vemos la soledad en la que está inmersa cuando contempla una fotografía de sus familiares que han muerto a causa de la guerra. Elsa acoge hospitalariamente en su casa a Roshental y a Maréchal: cura sus heridas, los sienta en su mesa y los esconde en su casa. La noche de Navidad Maréchal y Elsa se hacen amantes, porque para ellos lo importante tampoco es el idioma o la nacionalidad, sino el mutuo entendimiento y la ignorancia hacia las razones de la contienda. Los franceses, Elsa y su hijita inician una amistad provocada por la necesidad y el interés, pero que acabará siendo una amistad perfecta entre seres justos, querida por sí misma y generosa.

La gran ilusión en la película de Renoir es realmente la tolerancia. Boëldieu, a pesar de su concepto inicial de areté como virtud homérica, es capaz de adaptarse al dêmos, nueva fuerza transformadora de las relaciones sociales. La areté ya no se tiene, sino que puede ser conseguida por cualquier hombre. Esto explica su sacrificio final, pues ha comprendido que después de la Gran Guerra su mundo aristocrático no tendrá razón de ser, y así se lo hace saber a su amigo Rauffenstein, que ahora no es más que un inválido con el despreciable oficio de carcelero, mientras que las familias como los Rosenthal poseen media Francia. Los acontecimientos han propiciado la mezcla de las distintas clases sociales, pero el mundo natural se termina superponiendo al social, cultural e histórico llegando, incluso, a anularlo aceptando una ley universal.

Pero no todos los seres con conciencia de elite terminarán entendiendo la ley del mismo modo como en el caso de la señora Berthol (Marlene Dietrich) y del juez Ernst Janning (Burt Lancaster) de ¿Vencedores o vencidos? (Kramer, 1961). La primera es la viuda de un general nazi ahorcado por los aliados y el segundo un juez del régimen de Hitler; y ambos son representantes de la aristocracia del tiempo de los horrores. Los dos anhelan la reconstrucción nacional de su pueblo, 
pero ésta implica el olvido de las vidas destrozadas por su antiguo derecho positivo. Por este motivo fracasa la amistad entre la señora Bertholt y el juez norteamericano Dan Haywood (Spencer Tracy). Ambos son seres afines que gozan con la refinada compañía del otro - asisten juntos a conciertos, pasean, visitan monumentos, etc.-, e incluso surge entre ellos el deseo amoroso, pero su visión de cómo hay que vivir es tan radicalmente opuesta que la amistad deja de ser algo viable. La señora Bertholt no responderá a las llamadas telefónicas del juez Haywood, porque él no ha sucumbido al inmoralismo como una forma superior de comportamiento social. Para Haywood el derecho natural es anterior al derecho positivo, y por lo tanto tiene más valor. No es partidario de que dramas como los de Irene Hoffman (Judy Garland) o Rudolf Petersen (Montgomery Clift) sean pasados por alto, aunque estén perfectamente justificados por las barreras sociales o raciales. Algo similar sucederá entre Janning y Haywood. Entre los que surgirá a lo largo del proceso judicial una simpatía, la de los sabios que se reconocen, pero avocada, también, al fracaso por sus discrepancias en el concepto de lo justo y lo bueno.

La amistad condicionada por una conciencia de clase también tiene mucha fuerza en La cruz de hierro mediante dos personajes antagónicos: el mezquino capitán Stransky (Maximilian Schell) que encarna los valores de la vieja y cerrada aristocracia prusiana, mientras que el carismático sargento Rolfe Steiner (James Corbun) se convierte en el abanderado de la dignidad del hombre, sea cual sea su ascendencia social. Steiner será el que le hable a Stransky de la fuerza del dêmos, recordándole que el padre de Schubert fue un simple maestro de escuela y que el de Kant fue talabartero. Pero la gran diferencia entre ellos, más que en su concepción sobre las clases sociales, reside en la perspectiva moral con la que enfocan el mundo y sus actos: Stransky desde el egoísmo y Steiner estableciendo lazos de amistad con todos aquellos que le rodean. Este último posee las virtudes homéricas del guerrero que destaca en el combate, y las aristotélicas del hombre bueno que necesita de la amistad para estar en el mundo.

Otra gran película en la que priman los sentimientos y las pasiones frente a las ideologías es Roma, ciudad abierta (Rossellini , 1945) (verídica del sacerdote Luigi Morosini, por haber colaborado con los resistentes a la ocupación alemana. Al margen de la biografía real que inspira al 
director, es un filme de reconstrucción histórica en el sentido de que explica el contenido social, la mentalidad y el modo de vivir y de expresarse de una época (Caparrós Lera, 1998, pp. 35-37). Los personajes nobles se mueven por sentimientos universales - amor, compasión, piedad, amistad-, frente a los torturadores y asesinos nazis, que se mueven por la ideología del odio. La lucha por la moralidad y la honradez consigue superar barreras que permiten la amistad entre un sacerdote católico y un militante comunista.

\section{La amistad y el viaje moral: Apocalypse now y El corazón de las tinieblas}

La novela de Joseph Conrad El corazón de las tinieblas (1902) sirve de soporte argumental a la película de Francis F. Coppola Apocalypse now (1979), en la que también hay referencias a la poesía de T. S. Eliot, concretamente al poema "Los hombres huecos" (1925) y Cuatro cuartetos (19361942) $)^{2}$. Los relatos de Conrad y Coppola van más allá del conflicto imperialista y van a las contradicciones que alberga cualquier ser humano. Tanto el relato en off del capitán Benjamin L. Willard (Martin Sheen) como la parte final, la del encuentro de Willard con el coronel Walter E. Kurtz (Marlon Brando), son una recreación de la atmósfera conradiana. Son varios los elementos del filme que a medida que avanza va dejando de ser bélico para ser de tono casi místico, que son idénticos a los del relato de Conrad: el personaje de Kurtz y sus especulaciones morales acerca de la bondad y la maldad humanas; los guerreros nativos que custodian su refugio; el hombre escondido en la oscuridad y el cráneo que parece de marfil.

El viaje de Marlow y el de Willard resulta ser doble, pues se trata de un viaje iniciático: es físico y es moral. Éste último es el resultado de una identificación progresiva con el modo de entender el mundo por parte de Marlow y de Willard. La amistad que aparece en El corazón de las tinieblas y en Apocalypse now tiene su fundamento en el desdoblamiento. El personaje de Kurtz es un ser terrorífico que actúa como espejo del alma, es el gemelo relacionado con la muerte, por lo

\footnotetext{
2 Eliot escribió sobre Conrad: "Él es, en algún aspecto, la antítesis del Imperio (tanto como de la democracia); sus personajes encarnan la negación del Imperio, de la Nación, de la Raza casi, están terriblemente solos con lo Salvaje" (Eliot, 2015, p. 831). Es decir, niega los intereses que son origen de la discordia y la guerra.
} 
que la amistad consiste en una fuerte atracción hacia el ser que se va revelando idéntico al propio yo.

Conrad plantea la barbarie como la existencia propia del hombre agónico, mientras que la civilización no es más que la muerte, que comienza con el fin de todo ideal. El viaje al interior de Marlow marca la distancia insalvable del hombre europeo y colonizador con el hombre primitivo. Cuando llega a África y recorre el río Congo descubre la verdadera calaña de las empresas colonizadoras, y se irá deshaciendo de la idea un tanto infantil previa a su llegada. Es así como comienza a interesarse por Kurtz, porque ha sido capaz de entender lo difusa que es la línea que separa el Bien del Mal, y la doble moral que, los que son como él, practican:

La mente humana es capaz de cualquier cosa, porque todo está en ella, el pasado no menos que el futuro. Después de todo, ¿qué había allí? Alegría, temor, tristeza, devoción, valor, ira, ¿quién sabe?, pero aquello era la verdad, fuera lo que fuera, una verdad despojada de los atavíos del tiempo. Que los tontos se asombren y tiemblen, el que sabe puede enfrentarse con ello sin pestañear. Pero debe ser al menos tan hombre como los de la orilla. Debe hacer que esa verdad conozca su propia verdad íntima: su fuerza natural. ¿Principios? Los principios no valen para nada (Conrad, 1998, 22).

Mrs. Kurtz, ¿se ha vuelto loco o, por el contrario, es más lúcido que el resto de blancos? Se ha convertido en rey de las tribus cercanas participando en sus rituales, mantiene relaciones amorosas con una nativa y parece ser que coquetea con la antropofagia. En realidad, Marlow cuestiona la acción liberalizadora del blanco sobre el negro, aceptando, incluso, "un espectáculo salvaje [...] transportado de golpe a una oscura región de sutiles horrores" (Conrad, 1998, 149). El sentimiento amistoso es atracción hacia alguien que se revela como equivalente a la propia alma, que es capaz de hacer descubrir la verdad de sí mismo con su grandeza y miseria: "también él luchaba consigo mismo. Veía el misterio inconcebible de un alma que no conocía la moderación, ni la fe, ni el miedo, pero que, sin embargo, luchaba ciegamente consigo misma" (Conrad, 1998, 159). 
Apocalypse now da una visión desmitificadora de la guerra, y en sintonía con la crisis social iniciada de los años sesenta, y que se concentró, como apunta Gonzalo Muinelo (1987, p. 47), en tres oposiciones: "al empleo de armas, a los mitos del progreso y al poder socialmente constituido". Los héroes de la Segunda Guerra Mundial ya no existen, porque han sido reemplazados por soldados que han abandonado el código del honor y se refugian en las drogas. Las guerras las protagonizan hombres desquiciados por las atrocidades cometidas, y que no poseen nada digno de admiración en su conducta. Uno de estos soldados es Willard, que no ha logrado escapar del horror vivido en la jungla vietnamita ni siquiera bajo el efecto de las drogas. Vive, todavía, la pesadilla de la locura colectiva que resuena en la canción de The Doors: "This is the end, beautiful friend, the end, my only friend, the end...". Cuando unos oficiales irrumpen en la habitación de su hotel para encargarle una misión especial no sabe que su conciencia va a sufrir una transformación radical. Willard acudió a Vietnam con la idea de servir a su patria, de ser un ciudadano útil, pues es un hombre que vive en sociedad, y que, por lo tanto, acepta la amistad como necesidad o intercambio. La amicitia está ligada a la política, tal y como la entendía Cicerón en su primera época, y es, por lo tanto, un bien instrumental, aunque la conclusión final sea que la amistad se funda en la naturaleza que se perfecciona en la sociedad por medio de la ética (Laín, 1986, pp. 49-55). Pero Willard terminará profundamente decepcionado cuando sea consciente de la absoluta falta de moral de los militares norteamericanos, aunque él también participe de la crueldad imperante.

Ha de remontar el río, hasta llegar a Camboya, y allí encontrar al rebelde coronel Walter E. Kurtz y eliminarlo, porque se ha desentendido de una guerra que no comprende. Éste ya no obedece órdenes americanas, ha buscado un refugio en la selva, ha puesto a su servicio un ejército, que lo idolatra como si de un dios se tratara, y ha enloquecido de una forma animal. Así es como Willard comienza, como ya hizo Marlow, un viaje físico y moral:

¿A cuánta gente había matado yo? Eran seis y podía notar su último aliento en mi cara. Pero esta vez se trataba de un americano. Y un oficial. No podía creer que quisieran ente rrar a ese hombre. Casi mil condecoraciones. Condenar a alguien por asesinato en este sitio 
resultaba tan absurdo como una multa por exceso de velocidad en Indianápolis. No sabía lo que haría una vez llegado el momento (Coppola, 1979).

Willard hará el viaje con unos jóvenes soldados, pero a pesar de la cercanía no sentirá hacia ellos amistad, porque nada tienen en común. Por el contrario, cada vez se siente más atraído por la personalidad de Kurtz: “Cuanto más empezaba a leer, más le entendía” (Coppola, 1979). La simpatía surge, entonces, del conocimiento, no físico o superficial, sino del que ahonda en lo más íntimo del ser humano, aunque éste no sea fruto del contacto físico, sino de una especie de relación epistolar ${ }^{3}$ y en una sola dirección. También el encuentro con el nada ortodoxo teniente coronel Bill Kilgore (Robert Duvall) le provoca, si cabe, más dudas acerca de la moralidad de la misión que le ha sido encomendada: "Si ésta era la manera de hacer la guerra de Kilgore, me preguntaba qué se le reprochaba a Kurtz" (Coppola, 1979). Y por este motivo Willard no tarda en leer, en la carta que Kurtz envía a su familia, la justificación de su crimen, el asesinato de cuatro dobles agentes vietnamitas: "Actuamos como soldados. La crueldad muchas veces es simplemente clarividencia, hacer lo que hay que hacer, sin titubeos, inmediatamente. Estoy por encima de su moralidad tímida que, desde luego, no comparto" (Coppola, 1979).

Kurtz le muestra la verdad desnuda, porque un espejo no dice mentiras, ya que es un duplicado del yo, del otro uno mismo del que Aristóteles habla (Laín, 1986, p. 41). Después de la masacre innecesaria de la barca Willard se identifica plenamente con él, y remata a una mujer a pesar de que los muchachos la quieren llevar a un puesto de socorro: "Agujeros con una metralleta y después ponerles una venda. Todo mentira" (Coppola, 1979). La afinidad a la hora de enfocar las acciones origina una simpatía, la philothēs del Lisis platónico ${ }^{4}$, entre los dos hombres, que se hace patente definitivamente en el conocido monólogo de Kurtz ante Willard, clímax de la ambigüedad

3 El conocimiento de los actos de Kurtz por parte de Willard se produce a través de los numerosos documentos que el ejército de los Estados Unidos le facilita, y que irá leyendo y descifrando durante el viaje por el río; sin embargo, Willard buscará algo más que está fuera de la versión de la prosa oficial.

${ }^{4}$ Este diálogo el primer documento literario que indaga sobre el amor y la amistad y que de algún modo fija las ideas tradicionales sobre estos conceptos (Platón, 1981, p. 275). 
moral del filme, que tal vez sea fruto de "una experiencia histórica que no se acaba de asimilar" (Caparrós Lera, 1998, p. 107).

Los seres que pueblan Apocalypse now son seres tan desquiciados que, en general, las relaciones humanas se ven anuladas, y la amistad también, en favor de los instintos y pasiones, o mediante la evasión de la realidad gracias al consumo de drogas. Dado que el mundo, el de los perseguidores y el de Kurtz, es atroz, Willard solo tiene una opción para encontrar un poco de paz: sumergirse en el mundo de su propia intimidad (proaíresis). Además, él sabe, a diferencia de sus tres compañeros de viaje, que el infierno no termina con la vuelta a casa, ya ha regresado y ha visto lo que hay para los excombatientes. La amistad de Willard hacia su alter ego se alimenta del misterio, del no saber exactamente que puede encerrar la mente humana; pero también de la confianza, mientras que todos juzgan a Kurtz loco, el amigo espera una explicación que justifique sus actos.

\section{La amistad entre oficiales y soldados: La cruz de hierro.}

\section{¿Poder o liderazgo?}

La obra maestra de Sam Peckinpah nos presenta una visión de los soldados en combate si edulcorante. La acción transcurre en la Segunda Guerra Mundial, concretamente en 1943, durante la retirada de las tropas alemanas del frente ruso. En La cruz de hierro los hombres luchan sin saber por qué lo hacen; son víctimas de instancias superiores para las que tienen la función de simples marionetas y se sienten fuera de lugar. Se trata, en definitiva, de una historia sobre la desmoralización de los hombres en el frente. No es de extrañar, entonces, que éstos, en unas condiciones de vida durísimas y en un estado psicológico deplorable, necesiten de la amistad y de la lealtad de los compañeros. Y es en este contexto brutal donde los hombres necesitan de los líderes, que no son, necesariamente, los que ostentan el poder ${ }^{5}$.

${ }^{5}$ En el cine bélico existen dos tipos de oficiales — los que se preocupan por sus hombres y los que los utilizan con el fin de medrar-, y con respecto a esta cuestión existe un tópico que se da con mucha frecuencia: cuanto mayor es el número de estrellas de la guerrera menos les importa la suerte que corran los soldados. Pero también existen los oficiales, generalmente de bajo rango, que se desviven por los soldados rasos 
El cabo Rolfe Steiner es el líder indiscutible en La cruz de hierro, porque es inteligente, carismático, responsable, ofrece confianza y seguridad, cumple sus promesas, y su poder no lo ejerce de forma coercitiva; tanto es así que incluso sus superiores - el coronel Brand (James Mason) y el capitán Kiesel (David Warner) - lo estiman y respetan, porque son conscientes de su valor. Por el contrario, para el capitán Stransky, él representa un peligro, ya que lo ve capaz de despojarlo de una autoridad que en realidad no puede tener, porque la verdadera autoridad no se puede sustentar en el engaño y la manipulación psicológica. Steiner es el vir bonus que da sentido a su vida con una actitud moral y coherente en dos directrices: su respeto por las mujeres y los niños ${ }^{6}$, y su apego a la amistad. A pesar de las órdenes se niega a ejecutar a un niño ruso que cae prisionero, paradójicamente serán los rusos los que lo maten, porque para Stainer la infancia representa la esperanza. Con este niño establece una relación especial de amistad, y tanto es así que cuando se despiden le regala lo único que de valor posee, una pequeña armónica. Ésta ejerce la fuerza de lo que en maorí se llama ho, que es, como apunta Bruno Karsenti "el espíritu de la cosa dada, que hace que el presente tenga algo del donador, y cuya transferencia representa una influencia espiritual sobre el beneficiario del don" (2000, p. 104). El regalo del niño a Steiner no hay que entenderlo como un compromiso social, sino como una prueba de respeto y de reconocimiento a una amistad surgida en las condiciones más penosas.

despreciando los ascensos y las condecoraciones; incluso se podría hablar de otro tipo, el de los que piensan que necesariamente el poder de los despachos corrompe al soldado, por lo que se niegan a aceptar puestos de oficial.

${ }^{6}$ El tema de la infancia tiene una importancia crucial en La cruz de hierro, como se refleja en su estructura circular. La cinta comienza con las canciones de los alevines nazis y con imágenes de archivo de Hitler, para finalizar con esas mismas canciones, con imágenes de espeluznantes matanzas mucho más recientes y con una cita apocalíptica de Bertolt Brecht: "No os alegréis de su derrota pues, aunque el mundo resistió y detuvo al bastardo, la perra que lo concibió vuelve a estar en celo". Los niños encarnan el amor/amistad al género humano o philantrōpía y por ese motivo todos aquellos que los respetan, como Steiner, están capacitados para sentir amistad; pero Peckinpah nos advierte de que los que representan la esperanza pueden ser después los ejecutores de la violencia de la que han sido testigos. El juego infantil de los rayos de sol de Diezt (Michael Howka) será una de las pocas cosas que hagan sonreír a Steiner en el caos en que está inmerso. También en el respeto por la dignidad de las mujeres soviéticas, a pesar de vivir la violencia más cruda, pone en evidencia la actitud recta del líder y de los que son sus amigos, en clara oposición a los que se excluyen del mundo ético de la philía. 
Steiner posee una autoridad innata que emplea como herramienta para el bien común; no infunde temor, pero sí respeto; no es inaccesible, pero tiene un espacio psicológico propio; y tiene una gran seguridad en sí mismo. Es un hombre cínico y antinazi, que vive la guerra a pie de cañón y solo por eso puede ser un líder que, tan solo quiere sobrevivir junto a su batallón; ha hecho del jugarse la vida un oficio, un modo de vida, aunque no le otorga ningún sentido patriótico, incluso se le podría acusar de nihilismo: "El soldado alemán ya no lucha por la cultura de Occidente, ni por ese odioso partido. Lucha por sobrevivir" (Peckinpah, 1976).

Por el contrario, Stransky ensalza constantemente su imagen correcta y acicalada en todo momento que no es consciente de sus delirios megalómanos. Es un hombre indigno al que los demás no pueden amar, porque él no se ama así mismo, sino a una falsa imagen de sí construida con una condecoración - la Cruz de Hierro que otorga el Tercer Reich- que para su vergüenza pretende robar a quien verdaderamente la merece.

Stransky es uno más de los oficiales que conciben las relaciones humanas como un abuso de su poder, que no será el único que dispare contra sus hombres como el general Paul Mireau (George Macready) de Senderos de gloria (Kubrick, 1957) que tampoco dudará en hacerlo. El coronel Nicholson (Alec Guinness) hará trabajar como esclavos a sus hombres, a los que manda construir un puente sobre el río Kwai (Lean, 1957), con el fin de colmar su vanidad y grotesco egoísmo. El coronel Tall (Nick Nolte) de La delgada línea roja los conduce a una misión suicida, porque sabe perfectamente que ha de complacer a los que están por encima de él y que teme: "cuanto más cerca estas del césar mayor es el temor" (Malick, 2000). Tall tiene una idea maquiavélica con respecto a este tema, en el caso de que surja la duda de si es mejor ser amado o temido por sus subordinados, se decantará por lo segundo; además, su desconfianza en los demás es proverbial:

[...] los hombres tienen menos miedo de ofender al que se hace querer, que al que se hace temer; porque el amor está mantenido por un vínculo de obligación, que, dada la malicia humana, se rompe con cualquier motivo de utilidad propia; pero el temor se mantiene gracias al miedo al castigo que no nos abandona jamás. (Maquiavelo, 1999, 136). 
Y el capitán Dana Holmes (Philip Ober) de De aquí a la eternidad (Zinnemann, 1953), tendrá como adversario al sargento Milton Warden (Burt Lancaster), que defenderá a sus amigos de la implacable maquinaria del ejército, aunque también deje claro que el sistema castrense puede ser un hogar para jóvenes descarriados.

En general, todos aquellos que abusan de su poder presumen de infundir respeto, y creen que hacen ver que actúan en favor de los intereses de todos; en definitiva, entienden ingenuamente que su resentimiento los demás lo van a entender como el refrán popular de que "quien bien te quiere te hará Ilorar". Ellos solos construyen su propio discurso, pero éste no puede convencer a nadie que tenga una idea remota de lo que es la amistad y el compañerismo. Son seres tan inseguros que son incapaces de confiar en ningún semejante, y que, sin embargo, sí lo hacen en los emblemas de su vanidad y de su falta de autoridad: armas de fuego, bastones y varas. No es de extrañar que vean en estos atributos falsos la insignia de un ser excelente, ser perfecto moralmente, del que están muy lejos. Resulta patético el falso paternalismo y el falso interés por los soldados del general Mireau cuando cumple con su «desagradable obligación de ir a las trincheras» (Kubrick, 1957) donde dirá: "Veo que estás limpiando tu fúsil. No olvides que es el mejor amigo del soldado. Si le cuidas él te cuidará a ti también" (Kubrick, 1957). Holmes que piensa "que en el ejército no es el individuo lo que cuenta", y que, aunque un hombre pueda "tener convicciones y defenderlas", en el ejército "solo se puede obedecer" (Zinnemann, 1953), tiene exactamente la misma idea de la amistad que Mireau por lo que dará el siguiente consejo a la compañía: "El fúsil es vuestro mejor amigo; si se os encasquilla en combate puede significar la muerte" (Kubrick, 1957). Para ellos los instrumentos de fuerza responden perfectamente a lo que esperan de un amigo, tal y como afirma Ballin Mundson (George Macready) de su bastón ante Johnny Farrell (Glenn Ford).

La "amistad" de las armas resultará, sin embargo, muy peligrosa volviéndose en contra de aquellos que han alabado sus virtudes. Este lugar común está muy presente en Lucio Anneo Séneca (1984, L. 1으, XII): 
Indudable es que, como he dicho, la clemencia establece profunda diferencia entre el rey y el tirano: aunque uno y otro se encuentren rodeados de las mismas armas, el primero se sirve de ellas para asegurar la paz, el otro para reprimir intensos odios por medio de inmenso terror. Ni siquiera contempla sin miedo las mismas manos a que se ha confiado, y los excesos le llevan a los excesos contrarios; porque se le odia, porque se le teme y quiere que se le tema porque se le odia, citando aquel verso execrable que a tantos príncipes ha precipitado: Oderint, dum metuant... iDesgraciado de aquel que no sabe hasta dónde llega la rabia cuando los odios rebasan la copa!. (Anneo, 1984, XII).

Como ejemplo valga el caso del instructor de La chaqueta metálica (Kubrick, 1987), al que la supuesta "hermandad de los marines" sustentada sobre un autoritarismo forzado que nace de la brutalidad castrense extrema (Roch, 2008, pp. 195-197) no lo librara de morir a manos de su amado fúsil al que le dedicó una apasionada oración: "Éste es mi fúsil. Hay otros muchos, pero este es el mío. Mi fúsil es mi mejor amigo y es mi vida..." (Kubrick, 1987).

Y frente a los villanos, los que poseen una autoridad innata actúan, al mismo tiempo, de padres protectores y de amigos transgrediendo las órdenes de sus superiores o enfrentándose a ellos. El capitán Staros (Elias Koteas) de La delgada línea roja no mandará a todos sus muchachos contra el búnker y pedirá algo tan básico como agua para evitar que no se deshidraten. Muchas veces la búsqueda de concesiones para los de rango más bajo supone un auténtico dilema moral. Tal es el caso del coronel Dax (Kirk Duglas) de Senderos de gloria, que se encuentra en medio de dos bandos irreconciliables, en los que la guerra es vista desde mundos opuestos: el de los palacios donde reina la opulencia, y el de las trincheras donde solo existe el miedo a la muerte y la miseria. "El deber de los soldados era obedecer. Si esta orden era imposible, la única prueba hubieran sido sus cadáveres en el fondo de las trincheras" (Kubrick, 1957), le dirá el perverso Mireau. Dax respeta al ejército y quiere a sus hombres, pero se dará cuenta de la farsa altisonante en la que se ve inmerso: en el juicio en el que defiende a tres de sus hombres no se juzga la supuesta cobardía, sino que se deja patente el poder, desde luego físico, de los mandos sobre los que hacen una guerra de trincheras. 
La ignorancia sobre cuáles son las causas reales de los combates, el sentirse fuera de lugar completamente, y la aparición de conflictos con las jerarquías propicia la condena a la guerra. Una de las consecuencias del antibelicismo es el antimilitarismo, proyectado hacia los altos mandos, y hacia los que los adulan y sirven con el objeto de lograr beneficios personales. Pero la convivencia entre compañeros y la prolongación de los conflictos fomenta que para muchos la pesadilla de guerra sea una forma de vida. Sin lugar a dudas, éste es el caso de Steiner, al cual Eva, con la que ha mantenido una intensa relación de amor y amistad, le pregunta, lúcidamente, si le tiene tanto miedo a la vida como para esconderse en la guerra. Cuando abandona a Eva y acepta volver voluntariamente al frente será más crítico con una barbarie que le repugna, aunque no pueda zafarse de ella.

\section{El hombre, lobo o dios para el hombre}

[...] que el hombre es una especie de Dios para el hombre y que el hombre es un auténtico lobo para el hombre. Lo primero es verdad si comparamos a unos ciudadanos con otros; y lo segundo, si comparamos ciudades. En el primer caso hay una cierta analogía de semejanza con la Deidad, a saber: justicia y caridad, que son hermanas gemelas de la paz. Pero en el otro, hombres buenos han de defenderse adoptando como santuario las dos hijas de la guerra: el engaño y la violencia, o, dicho en términos más claros, una brutal rapacidad (Hobbes, 2000, pp.33-34).

Este texto de la célebre obra Del ciudadano, incluido en la epístola dedicatoria al conde de Devonshire, ilustra a la perfección la encrucijada en la que están los hombres cuando los avatares de la política rompen el equilibrio teórico del dêmos. La paradoja, como señala Jacqueline Lagrée (2000, p. 124). reside en la misma esencia de la democracia, porque, si bien, solo en ella es posible la solidaridad entre todos los ciudadanos, la rivalidad le confiere un carácter inestable. En el cine bélico este dilema del homo homini, o deus, o lupus, se resuelve, y así lo pensaba Bergson (Lagrée, 2000 , p. 124), como norma general, seleccionando lo primero para los compatriotas, y lo segundo 
para los extranjeros ${ }^{7}$. La política en las guerras es el punto de inflexión entre los dos extremos por los que el hombre puede optar. Ahora bien, la política no limita la posibilidad de ser bondadosos solo con aquellos que son políticamente afines; la libertad individual permite a la persona establecer vínculos amistosos de diversa índole tal como había manifestado el pitagorismo: hombre - hombre (de la misma ciudad), pero también, hombre - hombre (extranjero) y hombre - familia (rasgos físicos o morales idénticos). También Séneca será partidario de que todo ser humano, sea cual sea su ascendencia o clase, puede ayudar a los demás:

[...] dará como hombre a hombre del patrimonio común. [...] Mas hará todo esto con tranquilidad de espíritu e inalterable semblante. Así, pues, el sabio nunca será misericordioso, pero será caritativo, será útil a los demás; porque ha nacido para servir de apoyo a todos, para contribuir al bien público, del que a cada cual ofrece una parte: su bondad alcanza hasta a los malvados, que, cuando hay ocasión, reprende y corrige (1984, L. 2ㅇ, $\mathrm{VI})$.

El cine bélico está plagado de tipos duros, pero que son capaces de las mayores consideraciones cuando lo que se trata es la defensa y bienestar de los soldados que tienen a su cargo, pero inclementes con el contrario. No escatimarán medios, incluso arriesgando la propia vida, para recoger a los heridos, o, simplemente, para darles un poco de morfina que mitigue el dolor final. «Es una suerte que sea nuestro teniente» (Forrest Gump, Robert Zemeckis, 1994), será lo que afirme el ingenuo Forrest Gump (Tom Hanks) de su teniente, el teniente Dan (Gary Sinese), porque es un oficial en el que los suyos pueden confiar, aunque con el enemigo no tenga piedad. Welsh (Sean Penn) de La delgada línea roja permite que el muchacho enfermo no siga avanzando hacia el búnker, frente al también sargento Keck (Woody Harrelson) que se había mostrado menos transigente. Sin embargo, cuando este último esté gravemente herido, Witt (Jim Caviezel)

\footnotetext{
7 Con respecto a esta cuestión ya hemos visto que existen excepciones, son aquellos hombres que ni siquiera se respetan a sí mismos - Stransky, Mireau, Tall, Dana Holmes, etc.-, por lo que no es esperable que reconozcan la dignidad de sus compatriotas, y mucho menos la de sus adversarios. Éstos se situarían en el extremo límite de la animalidad del lobo, serían por lo tanto seres completamente deshumanizados.
} 
comentará: "Todo irá bien, aunque muera no ha fallado a sus hombres. Si no nos hubiese llevado hasta el terraplén estaríamos todos muertos" (Malick 2000). El desquiciado teniente coronel Kilgore de Apocalypse now pone durante los bombardeos a poblados de civiles vietnamitas La cabalgata de las walkirias de Wagner comentando "a mis hombres les chifla", y todavía le queda tiempo para preocuparse de las olas que originan los proyectiles, para que sus chicos puedan hacer surf. Este peculiar oficial ataviado con sombrero de ala ancha, emblema del Séptimo de Caballería y pañuelo amarillo al cuello entiende la amistad solo entre compatriotas, y por eso Willard afirma de él: "Yo creo que no era un mal oficial. Quería a su gente y uno se sentía seguro con él. Era de esos tipos que destella una luz misteriosa y presientes que no recibirás ni un arañazo" (Coppola 1979). No pestañeará a la hora de perseguir a aquellos que hagan daño a sus amigos, a los que les proporciona todo aquello recuerde el estilo de vida de la patria; pero hacia aquellos que le resultan extraños no sentirá amistad, ni la más mínima simpatía, ni siquiera un poco de compasión.

La amistad en sentido político, entendida como bien general de la humanidad, se impone en situaciones extremas sobre los intereses personales haciendo desgraciados, aunque con la conciencia limpia, a aquellos que sacrifican hasta lo que más desean. Un ejemplo es el de el cínico y práctico, aunque en el fondo sea un idealista, Rick Blaine (Humphrey Bogart) y la decidida Ilsa (Ingrid Bergman) en Casablanca. Cuando Rick ayuda a Victor Laszlo (Paul Henreid) a salvarse vuelve a ser un hombre comprometido con la justicia. Con el fondo de una Europa destrozada por el nazismo, Ilsa protagoniza una historia triangular que la hará debatirse entre el deber y el bienestar particular. Rick e Ilsa superan su propia naturaleza, se suprahumanizan, alcanzando la naturaleza del daímōn, que Victor ya había alcanzado antes con su abnegación.

Roma, ciudad abierta es la historia de grandes amistades entre hombres y mujeres que no se juzgan ni por sus creencias religiosas, ni por su militancia política, sino por un estar en el mundo que sea ético. Manfredi (Marcelo Pagliero), el jefe de la resistencia comunista italiana, la excepcional doña Pina (Anna Magnani) y el cura don Pietro (Aldo Fabrizi), pagaran con su vida, sin ceder al chantaje y a la tortura. 
La lucha por liberar de la miseria a los pobres se hace espacialmente triste y dramática, porque desenmascara la hipocresía de la ley. Ya Aristóteles había advertido del peligro que entraña una defensa radical de las pasiones o de la ley, éthos o nómos. En Tierra y libertad (Loach, 1994) hombres y mujeres ${ }^{8}$ combaten por la liberación de una explotación que cuenta con la complicidad de las leyes. David (Ian Hait), y los que están en su situación, no tiene una concepción romántica de la guerra, porque él es un joven obrero en paro que no tiene ninguna expectativa. Este aventurero entiende la amistad como un perfecto equilibrio entre el dios y el lobo, al que solo se puede llegar mediante el entendimiento mutuo. Antepone el bien de la comunidad universal al suyo propio soportando la suciedad, el frío, los piojos, el hambre, las dificultades para mantener relaciones sexuales, el cansancio y hasta la decepción.

El altruismo generado por la amistad no concluye, necesariamente, con la muerte del "otro yo"; sino que el sentimiento se puede seguir desarrollando, aunque privado de actividad: Forrest Gump realiza sin su querido Buba el sueño que él había ideado antes de morir. Otras veces, la muerte sí que supone el fin a cualquier posicionamiento que tienda hacia la esencia del ángel, repudiando socialmente el sentimiento amistoso: Marlow, a su regreso a Bruselas, mantiene la mentira y el buen tono que el "mundo civilizado2 le exige; y no existen garantías de que Willad explique al hijo de Kurtz la verdad inalterada.

En muchas ocasiones lo político y lo personal se mezclan de tal manera que resulta imposible delimitar la frontera entre lo uno y lo otro, y es en tales situaciones, donde el obrar virtuosamente se enfrenta violentamente con las pasiones más íntimas. A Steiner y a sus compañeros les duele la muerte del jovencísimo Diezt a manos de una muchacha rusa, pero no vengarán su muerte, y no

\footnotetext{
${ }^{8}$ En Tierra y libertad las mujeres, y esto es extraño en el cine bélico, mantienen una relación de camaradería y amistad con los hombres de igual a igual. La mujer en este tipo de películas, cuando aparece, tiene otro tipo de relación amistosa con el hombre porque simboliza el mundo antes de la guerra. Con respecto a esta cuestión conviene aclarar que hay distintos niveles de idealización de la figura femenina: encarnación de la Edad Dorada como la esposa de Jack (La delgada línea roja); o de un mundo en paz representado por Eva (La cruz de hierro) y por Elsa (La gran ilusión), y por los travestidos de los campos de prisioneros (La gran ilusión y en El puente sobre el río Kwai). Pero cuando los hombres están tan desquiciados que no logran distinguir la bondad de la maldad la amistad con las mujeres se hace imposible, por lo que solo se relacionan las que son seres degradados: prostitutas (La chaqueta metálica) y las chicas Playboy (Apocalypse now).
} 
solo por respetar la voluntad del propio Diezt, sino porque una represalia no hubiese sido justa. Sin embargo, no vacilarán en dejar en manos de las mujeres soviéticas e indefenso, al miembro del partido Zoll (Arthur Brauus), que previamente las ha humillado. De un dramatismo sobrecogedor es la reacción de Steiner cuando contempla, sin poder impedirlo, como Triebig (Roger Frizt), el esbirro de Stransky, dispara contra sus amigos después de haber logrado atravesar el fuego enemigo. Steiner no dudará ni un instante en disparar a Triebig, y en llevar a Stransky "al lugar donde crecen las cruces de hierro" (Peckinpah 1976).

Lee Prewitt (Montgomery Cliff) en De aquí a la eternidad se negará a boxear lo cual le acarreará numerosos arrestos y humillaciones, aunque su negación no solamente es fruto de su oposición a los métodos brutales de Dana Holmes; sino a los profundos remordimientos de conciencia por haber dejado ciego a un amigo durante un combate. Los marines Lee Prewitt y Angelo Maggio (Frank Sinatra) tendrán en Milton Warden a su mejor defensor del déspota Holmes, el cual mantiene un apasionado romance con Karen Holmes (Deborah Kerr), pero que no será esto lo que le haga despreciar al mezquino capitán.

Aristóteles en su primera ética afirma que solo la amistad permite al hombre ser feliz (Aristóteles, 1988, pp. 369-393) y que ella es el mejor aliciente para el desarrollo del pensamiento y para obrar de forma virtuosa. La amistad que es hermosa tiene su pleno desarrollo en la sabiduría del hombre bueno, pero para llegar a un ella es necesario el esfuerzo por parte del hombre para evitar la maldad (Arístóteles, 1993, p. 361). Y el camino hacia la sabiduría plena no es más que un proceso, que consiste en eliminar los obstáculos entre la animalidad del lobo y la humanidad, y entre la humanidad y la superhumanidad del dios. Se trata de que los hombres, que viven en sociedad, consigan dominar la rivalidad existente en la polis, en la que la discordia es, como la entendía Heráclito, el origen de todo. Si el hombre consigue abandonar la lacra de las pasiones ira, codicia, deseo de superioridad, autoritarismo, etc.- en favor de un compromiso, el del logos, que propicie la armonía cósmica, tal y como la entendía el estoicismo, alcanzara la mayor felicidad. El resultado que se logra es un hombre amigo de sí mismo, o de los que son como uno mismo 
(Kilgore, Willard, Dan, Milton Warden...); o, mejor aún, prójimo de los demás hombres (Steiner, Marechal, Von Rauffenstein...); y en casos excepcionales, amigo de Dios (Witt, Staros...).

\section{Filón de Alejandría y la amistad con Dios, y la amistad pitagórica hacia la naturaleza: La delgada línea roja.}

El tratado de Filón de Alejandría Todo hombre sabio es libre es un ejemplo de dialéctica estoica tamizada por el pensamiento cristiano. En él el autor habla de una primera parte complementaria a ésta y que hoy día se ha perdido, Todo hombre necio o malo es esclavo. La humanidad aparece dividida en sabios y en necios, pero la libertad es un privilegio de los primeros y está vedada para los segundos.

Para los integrantes de la Estoa, y en general para todo el estoicismo clásico, el sabio es un ser autosuficiente, libre, rico, sin carencias, contemplador de todos los bienes y unido inmediatamente a los dioses y al resto de sabios. La amistad entre los sabios está fundada en la búsqueda común y constante de la verdad, por lo que no se puede sostener sobre elementos pasionales. Sin embargo, la gran paradoja reside en el hecho mismo de que el sabio no necesitando amigos siempre los tiene. Séneca llega a afirmar, incluso, que el hombre sabio es de algún modo superior a los dioses, ya que su perfección es debida exclusivamente a sí mismo y a su esfuerzo, pero no gracias a la naturaleza como en el caso de los dioses.

Para Filón, sin embargo, el sabio no es independiente de Dios, sino que ambos conviven en una relación amistosa que se hace patente gracias a la virtud humana. Tampoco la moralidad del sabio depende exclusivamente de él mismo, ya que, para alcanzar la libertad, que es la felicidad, debe guiarse, también, por las leyes de la naturaleza: “..., un oráculo más alto que Zenón nos manda buscar una vida concluida o llevada de conformidad con la naturaleza" (Filón de Alejandría, 1962, p. 86). El contacto con Dios y con la naturaleza, que en última instancia es, siguiendo a Platón, un reflejo de la divinidad, es lo único que puede llevar al hombre al bien de la felicidad, entendida ésta como eudaimonía o estado de paz o serenidad interior: 
[...] el hombre sabio es feliz, lastrado y cargado con su elevada moralidad, que le confiere un dominio sobre todas las cosas, y así, fuera de toda duda y de toda pura necesidad el hom bre bueno es libre. Además, nadie negaría que los amigos de Dios son libres. (Filón de Alejandría, 1962, p. 37).

La gran contradicción en la que incurre Filón aparece cuando aborda el tema de la soledad del sabio. No se sorprende de que "no aparezca arrebañado en grandes multitudes", alejado, en la medida de lo posible, de "la turba de los irreflexivos" debido a que la necedad es vista como algo contagioso. Insistirá constantemente en el tópico de la esclavitud de las pasiones y en el de la opinión de la muchedumbre, ya que la comunidad política y religiosa es previa a la amistad humana. De este modo la obediencia a los padres o la del soldado no se pueden considerar estados de esclavitud. Para él el paradigma de hombre sabio es Moisés, ya que es amigo de Dios y obediente con las leyes. Pero, en última instancia, la libertad es el lugar de asilo de la virtud una vez que se han desdeñado lastres tales como el dinero, la fama y el placer. Después de liberarse de las rémoras del perverso el hombre bueno ya estará capacitado para vivir en comunidad y gozando de la amistad divina: "puesto que tenía a Dios como amigo, estaba ligado a poseer la felicidad absoluta, ya que no era un defensor débil el que él tenía, ni una persona olvidadiza de los derechos de la amistad, en Aquel que es el dios de los amigos y observa cuidadosamente las exigencias de la amistad" (Filón de Alejandría, 1962, p. 38).

El hombre consigue la plena felicidad cuando en su alma la sensatez, el dominio de sí mismo, la fortaleza y la justicia se erigen victoriosas frente a la ignorancia, la incontinencia, la cobardía y la codicia. Filón se refiere a la soledad como a un espacio psicológico y no físico, aunque en ocasiones el retiro sea el modo en que el hombre aprenda a gobernar su alma. Por este motivo los hombres buenos que aparecen en La delgada línea roja, aun estando en la compañía de sus semejantes logran la soledad espiritual.

Witt (Jim Caviezel) será el personaje en el que mejor se observan estos sentimientos encontrados. Por un lado, afirma que adora la compañía Charlie, porque es su familia, y por otro 
reincide en desertar de ella escondiéndose en una isla habitada por nativos. Es ahí es donde Witt se hace sabio porque aprende a deshacerse de todo aquello que es trivial gracias a la convivencia con el buen salvaje, que es capaz, a diferencia del hombre occidental, de vivir en armonía con sus iguales y con la naturaleza. Lo que le resulta más llamativo a Witt, que termina de escapar de los horrores de la guerra, es que los adultos de la isla paradisíaca conservan la candidez de los niños. Los nativos saben aceptar a Witt, porque para ellos la philía nace del hecho de que los hombres sean iguales fisiológicamente, y capaces de vivir armónicamente con los animales en un entorno capaz de proporcionarles todo cuanto necesitan: se trata de la relación de unión y entendimiento pitagórica. Witt tiene un corazón noble, pero necesitará del contacto con seres que desconocen la maldad para ser consciente de la doble vertiente de la naturaleza humana: el hombre es bueno en su nacimiento, pero también posee un instinto de destrucción que aflora cuando éste no domina las pasiones, y que hará que reflexione de la siguiente manera:

¿Qué significa esta guerra en el corazón de la naturaleza? ¿Por qué la naturaleza compite consigo misma? ¿Hay alguna fuerza vengadora en la naturaleza o no sólo una, sino dos? [...] Esta terrible crueldad ¿de dónde sale? ¿Cómo ha arraigado en el mundo? ¿De qué semilla, de qué raíz ha brotado y de quién es obra? ¿Quién nos mata, nos arrebata la vida y la vida y la luz; se burla de nosotros mostrándonos lo que podíamos haber conocido? ¿Acaso nuestra destrucción beneficia la tierra, ayuda a que nazca la hierba o que luzca el sol? También en día hay esta oscuridad, has vivido esta negra noche (Malick, 2000).

Witt sabe que la causa de la desdicha y de la maldad es el abuso de las facultades que Dios ha dado al hombre. Percibe la necesidad de que, para los hombres, tal como manifestó Rousseau en El Emilio, o de la educación, no haya oposición entre la naturaleza y la cultura. El buen salvaje tiene una vida sencilla y uniforme; y sus únicos males son la vejez y la enfermedad. Por el contrario, en su mundo, viciado por la guerra, predominan la confusión y el desorden. Antes de que lo obliguen a abandonar la isla tendrá la voluntad de ser libre porque, aunque no tenga la capacidad para ejecutarla, siempre gozará de la potencia de amar la libertad. Es un hombre civil por la fuerza, pero 
él se siente hombre natural. Witt ha descubierto que la desigualdad se sustenta en la siguiente distinción rousseniana de base pitagórica:

El hombre natural es todo para sí; él es la unidad numérica, el entero absoluto, que sólo tiene relación consigo mismo o con su semejante. El hombre civil no es más que una unidad fragmentaria que depende del denominador, y cuyo valor está relacionado con el entero, que es el cuerpo social. Las buenas instituciones sociales son aquellas que mejor saben desnaturalizar al hombre, quitarle su existencia absoluta para darle una relativa, y transportar el yo a una unidad común; de suerte que cada particular ya no se crea uno, sino parte de la unidad, y no sea sensible más que en el todo (Villar, 1996, p. 63).

Cuando él regresa a la compañía, al mundo del hombre civil, es arrestado a trabajar en el cuerpo de camilleros, pero el ver a sus compañeros caer en el campo de batalla le hace volver a la lucha valientemente. Sin embargo, a pesar de que sus acciones se encaminen hacia la destrucción de los enemigos japoneses, ha aprendido que "Ios rostros son un mismo hombre, un único ser" a pesar de que cada uno busque la salvación por sí mismo, "como una ascua separada de la hoguera". Witt es libre porque no odia, porque ha logrado deshacerse de la ira y del miedo y porque juzga iguales a todos los hombres, porque cuando nacen son idénticos:

Éramos una familia. Tuvimos que separarnos y nos distanciamos. Y ahora estamos en bandos enfrentados, nos arrebatamos la luz unos a otros. ¿Cómo perdimos la bondad que nos fue otorgada? La dejamos escapar, la desparramamos sin miramientos. ¿Qué nos impide extender la mano y alcanzar la gloria? (Malick, 2000).

Los soldados de La delgada línea roja tienen la orden de ocupar una colina en la que el enemigo, los "japos", han instalado un búnker. Los muchachos se ven movidos por el amor a sí mismos y a sus amigos, pero en el momento en que el "enemigo" se muestra con su rostro sienten repugnancia por su sufrimiento. Uno de los soldados exclama "iLe he dado! iHe matado a un japoiiUno menos!"; pero rápidamente su júbilo se torna espanto al percatarse de que el ser al que ha disparado tenía su misma naturaleza, y reflexiona: “iHe matado a un hombre! No hay nada peor, es peor que la 
violación, pero nadie me condenará por ello". Witt contempla horrorizado el cadáver de un japonés que mediante una voz en off le explicará su final: “¿Eres honrado, amable, en esto se basa tu confianza? ¿Todo el mundo te quiere? A mí también me querían. ¿Acaso imaginas que tu dolor será menos intenso porque amabas la bondad?"

En La delgada línea roja todos los hombres participan del conflicto social de la guerra, pero no todos lo verán del mismo modo: los sabios lo rechazan, mientras que los necios ven en él un modo de medrar a costa del sufrimiento ajeno. Además de Witt aparecen otros personajes que se refugian en la amistad con Dios, que a su vez se proyecta en los demás hombres, para alcanzar la excelencia moral de la que habla Filón capaz de darles la felicidad como el sargento Welsh (Sean Penn), el capitán Staros (Elias Koteas) o Jack. Welsh le dirá a Witt que "en este mundo un hombre en sí no es nada" y que la gente en su situación "se limita a cerrar los ojos para que nada le afecte", y sin embargo él no perderá de vista a sus soldados demostrando su sensatez, su fortaleza y la justicia de su espíritu. El sargento ama al conjunto de su compañía, pero, además, establece con cada uno de los muchachos, y en especial con Witt, una relación de carácter individual basada en el tópico de la llíada cuando Diomedes le habla de sí mismo a Ulises "Pues yendo dos juntos, uno percibe antes que el otro / cómo sacar provecho; en cambio quien piensa solo / más lenta tiene la mente y el ingenio más débil" (Homero, 2012, p. 527) y que Aristóteles recoge en su Ética nicomaquea: "«Dos marchando juntos», pues con amigos los hombres están más capacitados para pensar y actuar" (Aristóteles, 1988, p. 333). Welsh solo cree en "el mundo que se hace pedazos», en el que vive, aunque Witt le hable del otro que él ha visto. Con la muerte de su amigo, que se ha inmolado a favor de la compañía, Welsh comprende perfectamente el sentido de su amistad y de su sacrificio:

¿Dónde estuvimos juntos? ¿Quién eres tú que estuviste a mi lado? ¿Quién caminó conmigo? El hermano, el amigo. La oscuridad tras la luz, el conflicto tras el amor son el producto de una sola mente o las facciones de un mismo rostro. 
Esto es un ataúd, un ataúd móvil. Nos quieren muertos, o viviendo su mentira. Lo único que puede hacer aquí un hombre es encontrar algo que sea suyo, crear una isla para él sólo. Si no llego a conocerte en esta vida déjame sentir tu presencia. Una mirada de tus ojos y mi vida será tuya (Malick, 2000).

El capitán Staros aprovechará la soledad de la noche para hablar con Dios al que se refiere como "mi luz, mi guía", y esa amistad a Dios se manifiesta en la amistad hacia sus muchachos a los que abandonará aún a costa de su propio sacrificio. Jack, por su parte, identifica la amistad divina con el amor que siente hacia su mujer a la que tendrá presente en todas las situaciones, porque sabe que: "La guerra no ennoblece a los hombres, los convierte en bestias, corrompe su espíritu". Para Jack la vida anterior a la guerra fue una edad dorada en la que el tiempo transcurría felizmente, y en la que su alma salió lo suficientemente fortalecida como para adaptarse a las peores situaciones:

¿Quién eres tú que adoptas tan diferentes formas? De tu muerte nadie escapa, pero también eres la fuente de lo que ha de nacer. Eres gloria, misericordia, paz, verdad, aportas karma al espíritu, comprensión valor y colmas los corazones.

\section{$[\ldots]$}

¿Cómo podremos llegar a otras orillas, a las colinas azules? El amor, ¿de dónde procede? ¿Quién aviva su llama? Ninguna guerra podrá apagarla, ni robarla. Yo estaba prisionero y tú me liberaste (Malick, 2000).

Frente a los hombres justos, que a pesar de la guerra son capaces de vivir en paz, están los perversos incapaces de sentir amistad ni siquiera hacia sí mismos. El coronel Quintard (Jonh Travolta), el capitán Bosche (George Clooney) y, sobre todo el autoritario, antipático y frustrado coronel Tall (Nick Nolte) son esclavos de pasiones como la codicia, la ignorancia, la cobardía y la incontinencia, por lo que sus semejantes, incluso los más cercanos, no podrán ser sus amigos. El coronel Tall es un personaje completamente asimilado por la peor idea de civilización, y tanto es así, que no duda en afirmar despreciativamente en una conversación con John Staros: "Mire esta selva, 
esas lianas que se enredan entre los árboles y lo engullen todo. La naturaleza es cruel...". El profundo desprecio que manifiesta hacia la naturaleza es proporcional al que siente hacia todos aquellos que sean un escollo en el camino hacia sus fines egoístas. Tall pertenece al grupo de los hombres ignorantes, y por lo tanto al de los esclavos, de los que habla Filón capaz de hacer morir a otros por «una guirnalda de acebuche o de apio», pero no por una gloria mayor: "el morir por la libertad, el amor a la cual está en verdad mucho más arraigado en el alma que ninguna otra cosa, no como accesorio casual, sino como una parte esencial de su unidad, y no puede amputarse, sin que todo el conjunto sea destruido como consecuencia de ello" (Filón de Alejandría, 1962, p. 67).

\section{Conclusión}

En las películas, aunque hay muchos ejemplos más sin salir del género, sobresalen los héroes arquetípicos y sus antagonistas. Los primeros son aquellos capaces de sacrificarse por los suyos, que en numerosas ocasiones traspasan a los hermanos. Los segundos se rigen por el principio etnocéntrico en el que los suyos son el "pueblo elegido» y los que se opongan deben ser aniquilados mediante la discordia-combate. Pero en un escenario de ruina histórica fruto de una degradación moral prima una épica de la violencia y, por lo tanto, la imposibilidad del heroísmo.

La guerra como hecho social que ha estado presente en todas las sociedades organizadas la hacen humanos organizados jerárquicamente. Los que participan en ella lo hacen desde dos posturas: la de los que la consideran connaturalmente mala, destructora de la sociedad y desintegradora de la moral; y la de los que la consideran el medio eficaz para demostrar la valía de las naciones mejores, capaces de progresar, frente a las ineptas que solo pueden ser sometidas mediante la violencia por las idóneas. En las obras analizadas algunos personajes parten de esta segunda postura heredera del nacionalismo romántico y del darwinismo social, pero tras la pérdida de la inocencia, Wilard es un buen ejemplo, reniegan de las vetustas concepciones del heroísmo y del progreso. Ellos inician un viaje interior desde la emoción a lo racional en el que deslegitiman la violencia contra otros seres humanos. 


\section{Referencias}

Aristóteles (1988). Ética nicomaquea, E. Lledó (Ed.). Madrid: Gredos.

Caparrós, J. M. ${ }^{\text {a }}$ (1998). La guerra de Vietnam, entre la historia y el cine. Barcelona: Ariel.

Conrad, J. (1998). El corazón de las tinieblas y otros relatos. Madrid: Valdemar.

Coppola, F. F. (1979). [Filme] Apocalypse Now. EEUU.

Curtiz, M. (1943). [Filme] Casablanca. EEUU.

Dmytryk, E. (1947). [Filme] Encrucijada de odios. EEUU.

Eliot, T. S. (2015). Poesías completas. I., C. Ricks, J. McCue y J. L. Rey (Eds.). Madrid: Visor.

Filón de Alejandría (1962). Todo hombre bueno es sabio. Madrid: Aguilar.

Hobbes, T. (2000). De Cive, C. Mellizo (Ed.). Madrid: Alianza Editorial.

Homero (2012). Ilíada, F. J. Pérez (Ed.). Madrid: Albada.

Laín, P. (1986). Sobre la amistad. Madrid:Esasa.

Maquiavelo, N. (1999). El Príncipe/La Mandrágora, H. Puigdoménech (Ed.). Madrid: Cátedra.

Macherey, P. (2000). El Lisis de Platón: dilema entre la amistad y el amor. En Jankélévitch, S. y B.

Olgivie (Dirs.), La amistad. En su armonía, en sus disonancias, (pp. 60-79), Barcelona: Idea Books.

Karsenti, B. (2000). ¿Hace la amistad donación de sí? En Jankélévitch, S. y B. Olgivie (Dirs.), La amistad. En su armonía, en sus disonancias, (pp. 96-109), Barcelona: Idea Books.

Kramer, S. (1961). [Filme] ¿Vencedores o vencidos? EEUU.

Kubrick, S. (1987). [Filme] La chaqueta metálica. EEUU.

Kubrick, S. (1957). [Filme] Senderos de gloria. EEUU.

Lean, D. (1957). [Filme] El puente sobre el río Kwai. GB.

Loach, K. (1994). [Filme] Tierra y libertad. GB-España-Alemania.

Malick, T. (2000). [Filme] La delgada línea roja. EEUU.

Muinelo, G. (1987). Sociología del cine de guerra. SI., Capitanía General de la VII Región Militar.

Peckinpah, S. (1976). [Filme] La cruz de hierro. GB/Alemania.

Platón (1981). Diálogos. 1, E. Lledó Iñigo (Ed.). Madrid: Gredos.

Reed, C. (1949). [Filme] El tercer hombre. GB.

Renoir, J. (1937). [Filme] La gran ilusión. Francia.

Roch, E. (2008). Películas clave del cine bélico. Barcelona-México-Buenos Aires: Robin Books.

Rossellini, R. (1945). [Filme] Roma, ciudad abierta. Italia. 
Séneca, L. A (1984). De la clemencia. Obtenido el 2 de junio de 2020 desde

http://www.cervantesvirtual.com/obra-visor/de-la-clemencia--0/html/ff0a2e94-82b1-11dfacc7-002185ce6064 2.html

Vidor, C. (1946). [Filme] Gilda. EEUU.

Villar, A. (1996). Rousseau (1712-1778). Madrid: Ediciones del Orto.

Zinnemann, F. (1953). [Filme] De aquí a la eternidad. EEUU. 